Article

\title{
Structural Diversity of Peptoids: Tube-Like Structures of Macrocycles
}

\author{
Claudine Nicole Herlan ${ }^{1}$, Katharina Sommer ${ }^{1}$, Patrick Weis ${ }^{2}$, Martin Nieger ${ }^{3}$ and Stefan Bräse ${ }^{1,4, *(\mathbb{D})}$ \\ 1 Institute of Organic Chemistry, Karlsruhe Institute of Technology, Fritz-Haber-Weg 6, \\ 76131 Karlsruhe, Germany; claudine.herlan@kit.edu (C.N.H.); katharina_sommer@posteo.de (K.S.) \\ 2 Institute of Physical Chemistry, Karlsruhe Institute of Technology, Kaiserstr. 12, 76131 Karlsruhe, Germany; \\ patrick.weis@kit.edu \\ 3 Department of Chemistry, University of Helsinki, P.O. Box 55 (A.I. Virtasen aukio 1), \\ FIN-00014 Helsinki, Finland; martin.nieger@helsinki.fi \\ 4 Institute of Biological and Chemical Systems-Functional Molecular Systems, Karlsruhe Institute of \\ Technology, Hermann-von-Helmholtz-Platz 1, 76344 Eggenstein-Leopoldshafen, Germany \\ * Correspondence: stefan.braese@kit.edu
}

Citation: Herlan, C.N.; Sommer, K.; Weis, P.; Nieger, M.; Bräse, S.

Structural Diversity of Peptoids: Tube-Like Structures of Macrocycles. Molecules 2021, 26, 150.

https://doi.org/10.3390/molecules 26010150

Received: 19 November 2020 Accepted: 24 December 2020 Published: 31 December 2020

Publisher's Note: MDPI stays neutral with regard to jurisdictional clai$\mathrm{ms}$ in published maps and institutional affiliations.

Copyright: (C) 2020 by the authors. Licensee MDPI, Basel, Switzerland. This article is an open access article distributed under the terms and conditions of the Creative Commons Attribution (CC BY) license (https:// creativecommons.org/licenses/by/ $4.0 /)$.

\begin{abstract}
Peptoids, or poly- $N$-substituted glycines, are characterised by broad structural diversity. Compared to peptides, they are less restricted in rotation and lack backbone-derived $\mathrm{H}$ bonding. Nevertheless, certain side chains force the peptoid backbone into distinct conformations. Designable secondary structures like helices or nanosheets arise from this knowledge. Herein, we report the copper-catalysed alkyne-azide cycloaddition (CuAAC) of macrocycles to form innovative tubelike tricyclic peptoids, giving access to host-guest chemistry or storage applications. Different linker systems make the single tubes tuneable in size and enable modifications within the gap. An azobenzene linker, which is reversibly switchable in conformation, was successfully incorporated and allowed for light-triggered changes of the entire tricyclic structure.
\end{abstract}

Keywords: peptidomimetics; tricyclic peptoids; CuAAC; foldamers

\section{Introduction}

Fundamental knowledge of the relationship between structure and function is a principal topic in both biological and material science. Rational design of conformationally stable macromolecules gives access to various applications regarding catalysis, host-guest chemistry, and cargo transport. Peptoids, or poly- $N$-substituted glycines, have been shown to form stable secondary structures, such as macrocycles [1-3], helices [4-6], or even nanosheets [7-10]. As bioinspired oligomers, peptoids possess antimicrobial characteristics [11-23] and hold promise for effective pharmaceuticals [20,24-27]. Attached to catalysts, they can induce enantioselectivity by structure $[28,29]$. In the form of nanosheets, peptoids act as molecular sensors or artificial membranes [7,8,30-34].

The submonomer method, firstly described by Zuckermann et al. [35], gives access to an infinite number of structurally diverse oligopeptoids, as various amines are easily introduced as sidechains. This remarkable diversity provides the basis for rationally designed functional foldamers that render peptoids a promising substance class for various applications.

Although the peptoid backbone is highly flexible due to its rather free rotating methylene unit, it can be forced into distinct conformations by a selection of certain sidechains. Thereby, aniline derivatives favour trans-conformations, while some aliphatic amines cis-conformations (Scheme 1) [36-40]. 


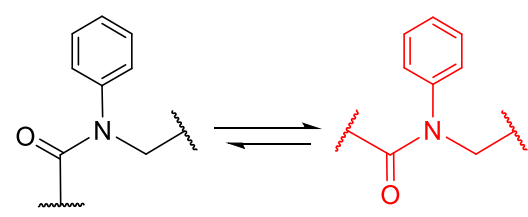

(a)

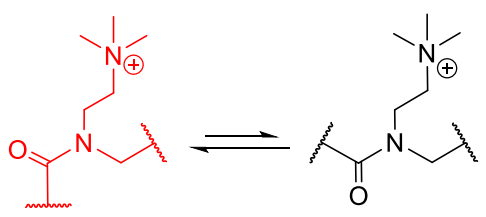

(b)

Scheme 1. Conformational equilibrium of a peptoid backbone. (a) N-aryl sidechain enforcing trans-conformation [36] and (b) positively charged $\mathrm{N}$-alkyl sidechain favouring cis-amide conformation [40].

Secondary structures can thus be induced via sequence control [41,42], but the scope of conformational permutations and the influence of certain side chains still have not been fully investigated. To constrain secondary structures, peptoid macrocycles of different sizes have been synthesised $[1,2,37,38,43-48]$. Among them, octameric macrocycles whose spatial structures were determined via X-ray crystallography and nuclear magnetic resonance (NMR) techniques $[3,37,38,43,44,48,49]$. Cyclic octamers were capable of performing hostguest interactions within their cavity [38,44,49] and could be further modified using coppercatalysed alkyne-azide [3 + 2] cycloaddition (CuAAC) [37,50,51]. CuAAC is a high-yielding, bio-orthogonal method that enables fast and facile modifications $[49,50]$. Kirshenbaum et al. reported the use of this kind of "click" chemistry to form cyclic peptoids [2,51]. By CuAAC of distinct side chains, the group was, furthermore, able to build up bi- and tricyclic structures [37].

To date, only one of these tube-like tricyclic structures is known (Figure 1). It was built up by CuAAC of two cyclic octamers with one alkyne and one azide moiety each [37]. Herein, we report the design of further rigidified tubular structures with modified linkage structures to enlarge the applicability of these unique peptoid macrocycles.

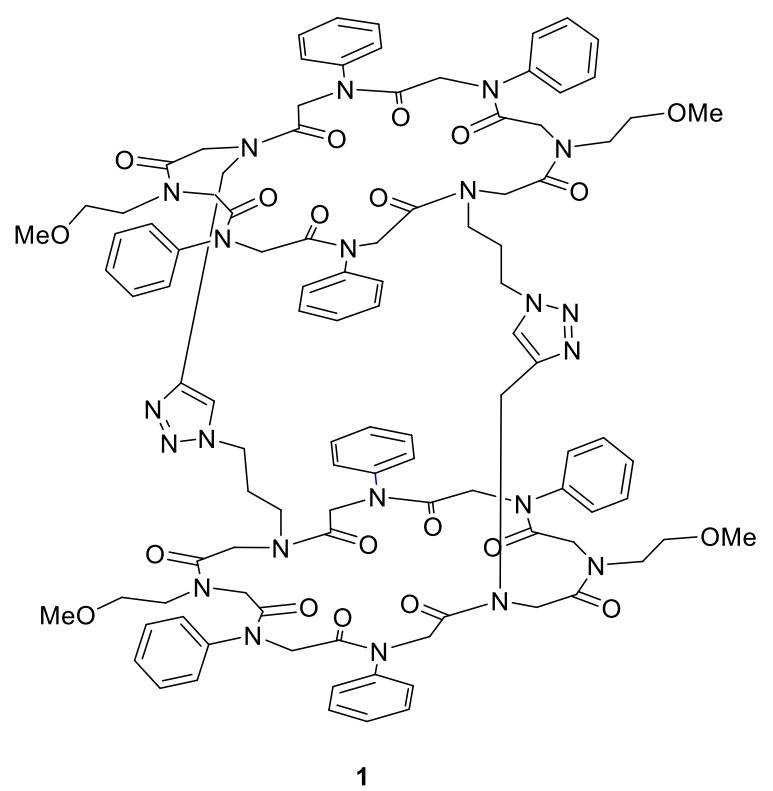

Figure 1. Tricyclic peptoid reported by the group of Kirshenbaum in 2012 [37].

\section{Results and Discussion}

\subsection{Design and Synthesis of Cyclic Peptoids}

The stepwise synthesis of peptoid macrocycles was carried out using the published submonomer method on solid support [35]. Acetylation and substitution steps were alternated until the desired chain length was achieved. After cleavage from the resin, linear precursors were converted in the solution without further purification. Cyclisation was 
carried out according to a protocol by Kirshenbaum et al. [1] without exceeding the peptoid concentration of $4.80 \mathrm{mM}$ to circumvent dimerisation (Scheme 2).

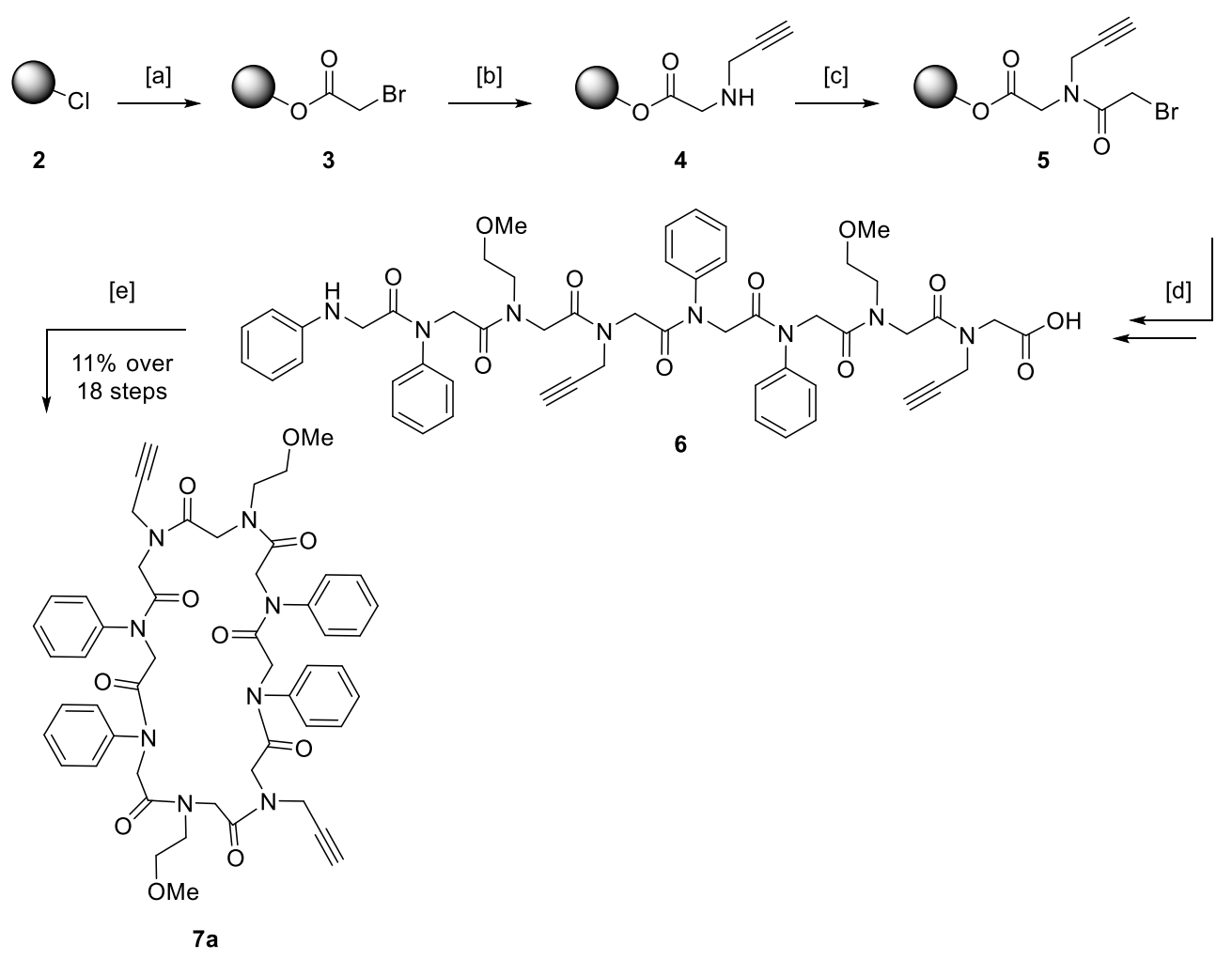

Scheme 2. A general approach for the stepwise synthesis of cyclic peptoids as derivatives of model structure 7a, including solid-phase synthesis on a chlorotrityl chloride resin (2) and cyclisation of the linear precursor in solution. (a) Bromoacetic acid, $N, N^{\prime}$-diisopropylethylamine, methylene chloride (DCM), $21^{\circ} \mathrm{C}, 1 \mathrm{~h}$; (b) propargylamine, $N, N^{\prime}$-dimethylformamide (DMF), $21^{\circ} \mathrm{C}, 1 \mathrm{~h}$; (c) bromoacetic acid, $N, N^{\prime}$-diisopropylcarbodiimide, DMF, $21^{\circ} \mathrm{C}, 30 \mathrm{~min}$; (d) (1). Alternating coupling of a desired amine following (b) and bromoacetic acid following (c); (2). hexafluoroisopropanol, DCM, $21^{\circ} \mathrm{C}, 30 \mathrm{~min}$; (e) PyBOP, DIPEA, dry DCM, $21^{\circ} \mathrm{C}, 16 \mathrm{~h}$.

By combining both solid- and liquid-phase techniques, plenty of peptoid macrocycles were readily accessible. Alkyne and azide moieties were incorporated to give access to post-synthetic modifications via CuAAC [50].

Peptoids were designed with the objective of the final backbone topology $c-c-t-t-c-c-t-t$, where " $c$ " indicates cis-conformation and " $t$ " indicates trans-conformation of the singlepeptoid subunits. In our previous study, structural data of a macrocyclic octamer similar to peptoid 7a that showed the desired backbone conformation were obtained [38]. Thereby, incorporation of $\mathrm{N}$-aryl amines stabilised the trans-amide structure elements. Different $\mathrm{N}$-alkyl amines gave access to cis-conformations, ensuring the spatial arrangement required for cyclisation. Based on these former results, peptoid $7 \mathbf{a}$ was contrived to represent the model structure of every macrocycle synthesised.

Considering further cycloaddition reactions, each peptoid was functionalised with either two alkyne or azide moieties. This design should enable the combination of two different macrocycles to form a tricyclic structure via intermolecular CuAAC of their sidechains. Functional amines capable of the click reaction were both aliphatic and aromatic. Four different cyclic peptoids (7a-7d, Table 1$)$ were synthesised according to the general approach described in Scheme 2. The cyclic octamers consist of four aryl and alkyl building blocks each. The respective monomers were arranged pairwise to ensure the desired backbone topology. Macrocycles $\mathbf{7 a}$ and $\mathbf{7 b}$ contain two adjacent anilines, as well as aliphatic functionalities as capable moieties for cycloaddition next to a methoxyethyl 
residue. Peptoids $\mathbf{7} \mathbf{c}$ and $\mathbf{7 d}$ are decorated with para-substituted anilines and two adjacent methoxyethyl sidechains.

Table 1. Synthesised eight-membered cyclic peptoids 7a-7d, capable of copper-catalysed alkyneazide cycloaddition (CuAAC).

\begin{tabular}{cccc}
\hline \\
Macrocycle
\end{tabular}

Purification was carried out via preparative reverse-phase high performance liquid chromatography (HPLC) solely after the cyclisation step. Product formation was confirmed via matrix-assisted laser desorption/ionization-time of flight (MALDI-TOF) measurements. Macrocycles $7 \mathbf{a}-7 \mathbf{d}$ were obtained in moderate yields ( $8.0 \%$ to $25 \%$ ) over 18 steps each. Purity was determined by integration of analytical reverse-phase HPLC traces and turned out to account for $87 \%$ to $99 \%$.

\subsection{Topology of Cyclic Peptoids}

A precondition for successful CuAAC of two macrocycles is a defined spatial arrangement of the alkyne and azide moieties. Both structural elements have to point upward or downward on the backbone, but necessarily in the same direction. Only one 3D structure of macrocyclic octamers resembling the synthesised ones is known from the literature [38]. Vollrath et al. published crystallographic data of a peptoid similar to macrocycle 7a in 2013. The building blocks of the published octamer comply with the ones of structure $7 \mathbf{a}$, but the positions of both the two aliphatic alkyne side chains and the methoxyethyl residues are interchanged. The backbone of this similar macrocycle showed the desired topology $c-c-t-t-c-c-t-t$, with sidechains pointing alternatingly up and down and both alkyne moieties located on the same side of the ring level.

It was assumed that peptoid $7 \mathbf{a}$ would be arranged in the same topology due to structural analogy. Unfortunately, no measurable crystals of 7 a were obtained. However, macrocycle $\mathbf{7 b}$, equipped with two aliphatic azides instead of the alkyne moieties, was successfully crystallised. X-ray diffraction experiments revealed its stabilised structure (Figure 2). 


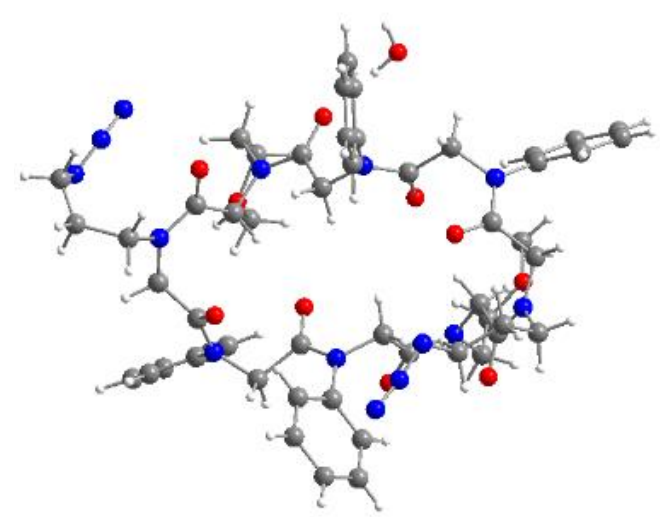

(a)

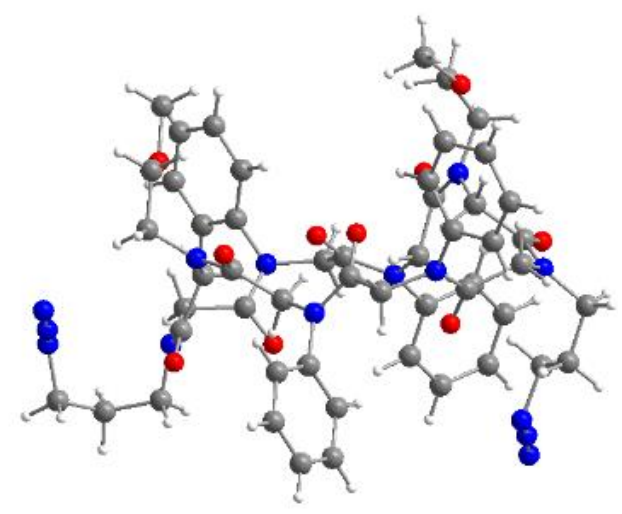

(b)

Figure 2. Molecular structure of cyclic peptoid $7 \mathbf{b}$ revealing the backbone topology $c-c-t-t-c-c-t-t$ with both aliphatic azides located on the same side of the ring level. (a) Top view; (b) side view.

Comparison of the structural data of the previously published octamer and peptoid $7 \mathbf{b}$ disclosed an equal backbone topology, including identical angles [38]. The sidechains are alternatingly located above and below the ring level, with both azide moieties pointing in the same direction. In contrast to propargylamine, the functional group of azidopropylamine is separated by three methylene units. The enlargement of conformational freedom by rotation around carbon single bonds makes the latter more flexible.

For cyclic octamers with aromatic alkyne or azide moieties, like peptoids $\mathbf{7 c}$ and $\mathbf{7 d}$, neither conformational data nor information about the orientation of both functionalisable groups have been found so far. Measurable crystals of peptoid 7c were obtained after multiple attempts, and their structure was elucidated via X-ray diffraction (Figure 3).

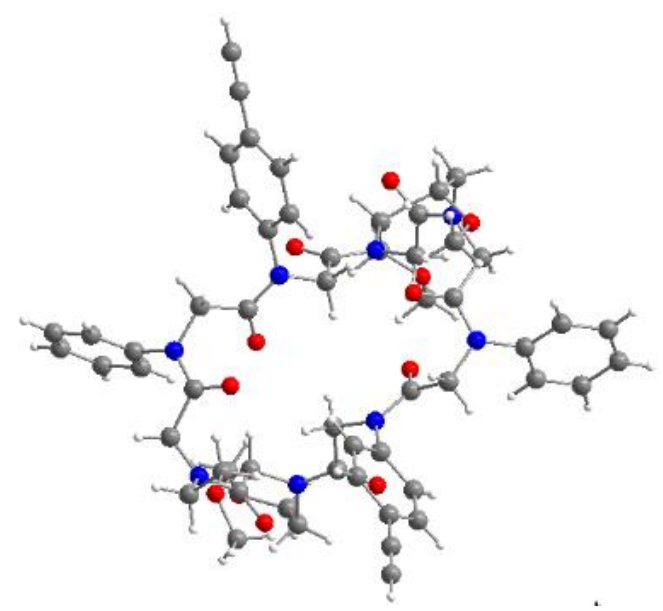

Figure 3. Molecular structure of one of the two independent molecules of the cyclic peptoid 7c decorated with two aromatic alkynes. The structural data coincide with those obtained for macrocycle $\mathbf{7 b}$.

The backbone topology equals the one known from other eight-membered macrocycles $[1,38]$. Again, the side chains are alternatingly located above and below the ring level, resulting in both alkyne moieties pointing into the same direction. These data coincide with those of the cyclic octamers $7 \mathbf{a}$ and $7 \mathbf{b}$ [38]. Due to the aromatic systems introduced, the functionalisable groups were rigidified compared to derivatives decorated with aliphatic moieties.

Although no measurable crystals of macrocycle $\mathbf{7 d}$ could be obtained, a similar conformation was expected due to the strong structural similarities to the remaining three macrocycles $7 \mathbf{a}-7 \mathbf{c}$. 


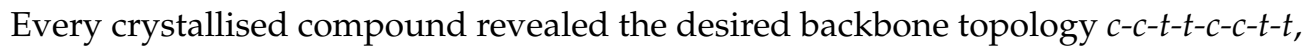
as proven for model structure 7a [38]. Aliphatic and aromatic azides, as well as alkynes, were successfully incorporated, and the design allowed for a location on the same side of the ring level. The latter constitutes a prerequisite for further modifications via CuAAC to design tricyclic tube-like structures.

\subsection{CuAAC of Two Cyclic Peptoids}

Copper-catalysed alkyne-azide cycloaddition is an effective method for crosslinking different structures. The four macrocycles mentioned were conjugated pairwise via CuAAC following a modified protocol by Jagasia et al. [52]. Catalysis was performed with tetrakis(acetonitrile)copper(I) hexafluorophosphate $\left(\mathrm{Cu}\left(\mathrm{CH}_{3} \mathrm{CN}\right)_{4} \mathrm{PF}_{6}\right)$ and 2,6-lutidine. The reaction was carried out in dry methylene chloride under inert conditions. Monitoring of the product formation via analytical reverse-phase HPLC revealed a reaction time of three days for every starting material to be converted. Subsequent purification was carried out via preparative reverse-phase HPLC.

CuAAC of peptoids $7 \mathbf{a}$ and $\mathbf{7 b}$, decorated with aliphatic functional groups, yielded the tricyclic compound 8 (Scheme 3).

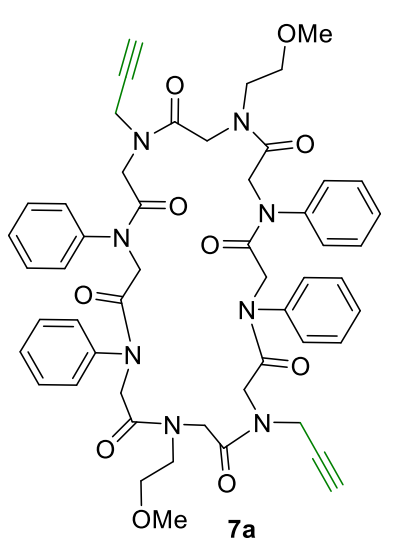

[a] $\downarrow 7 \%$

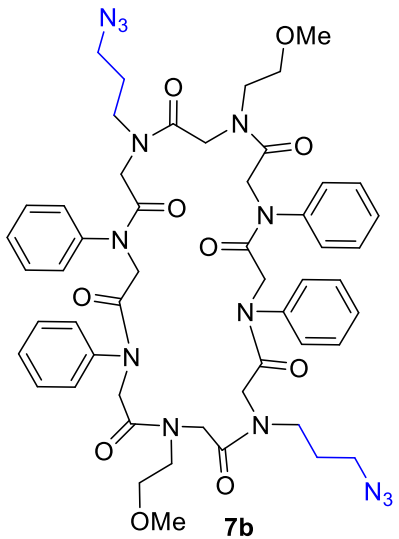

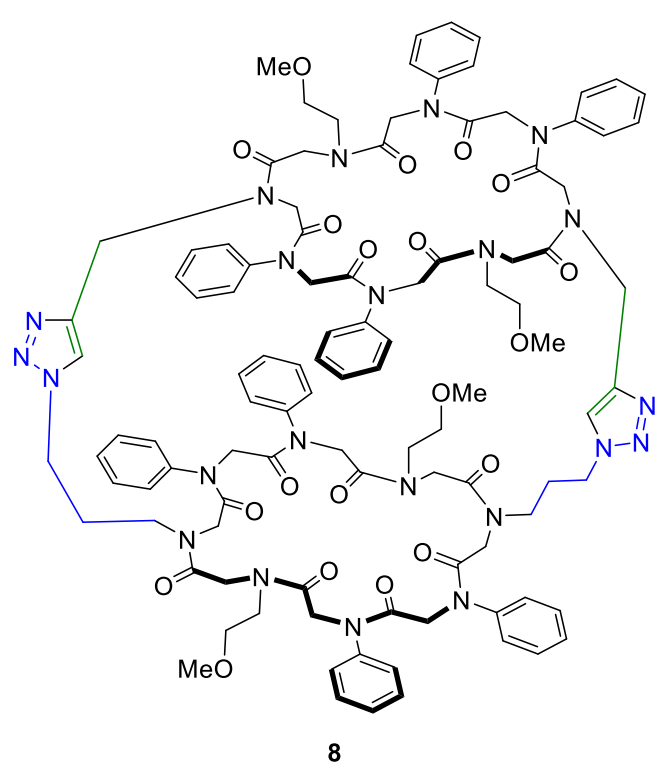

Scheme 3. CuAAC of peptoids $7 \mathbf{a}$ and $7 \mathbf{b}$ decorated with aliphatic functional groups. (a) 2,6-Lutidine, $\mathrm{Cu}\left(\mathrm{CH}_{3} \mathrm{CN}\right)_{4} \mathrm{PF}_{6}$, dry DCM, $21{ }^{\circ} \mathrm{C}, 3$ days.

The tube-like structure was isolated in $7 \%$ yield. Analysis via MALDI-TOF and analytical HPLC revealed product formation with a purity of more than $99 \%$. To validate conversion, IR measurements of both the azide-functionalised starting material and the 
final tricycle were taken. The characteristic azide band visible in the IR trace of peptoid $7 \mathbf{b}$ was omitted in the product spectrum. This measurement verified the formation of the tricyclic structure with both azide moieties converted into a triazole.

The CuAAC of the two macrocycles decorated with aromatic alkynes and azides (7c and $7 d$ ) was carried out following the procedure mentioned above. Product 8 was isolated in $6 \%$ yield and $98 \%$ purity (Scheme 4 ).<smiles>C#Cc1ccc(N(CC(=O)N(CC(=O)N(CCOC)CCOC)C(=O)CN(CC(=O)N(CCOC)CCOC)C(=O)CN(CC(=O)N(CCOC)CCOC)c2ccccc2)C(=O)CN(CC(=O)N(CCOC)CCOC)c2ccccc2)cc1</smiles>

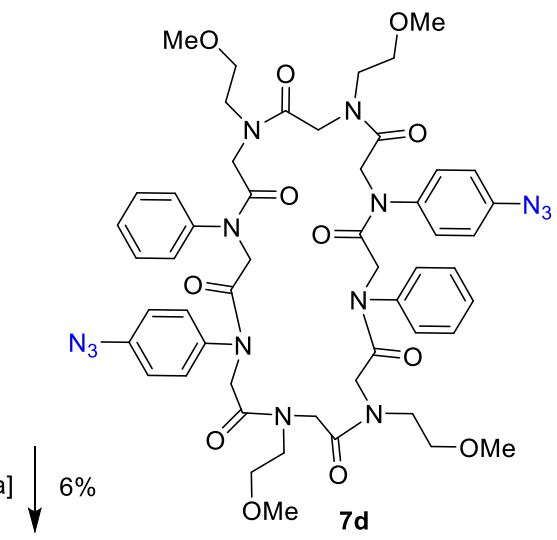

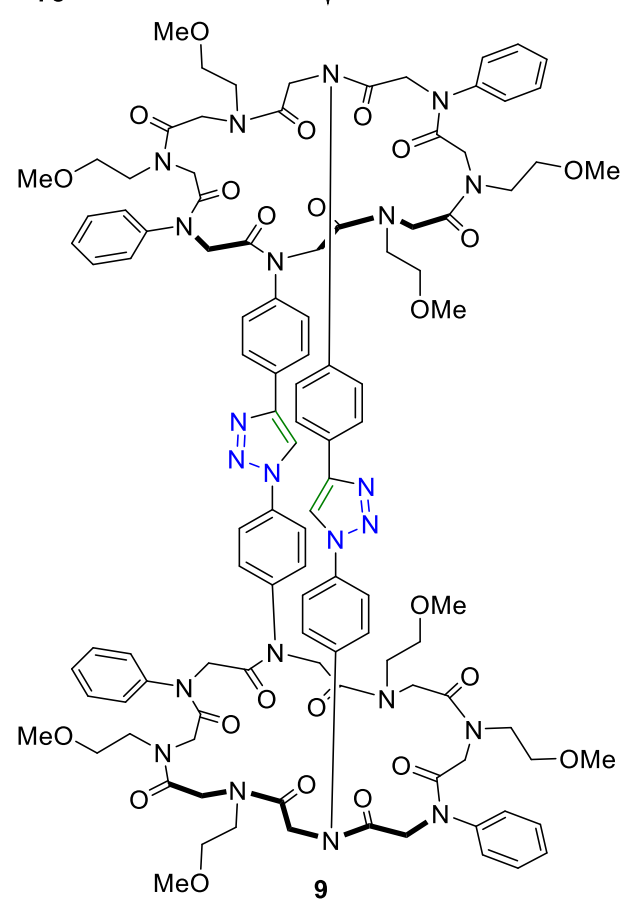

Scheme 4. Tricycle 9 as a product of the CuAAC of peptoids $7 \mathrm{c}$ and $7 \mathrm{~d}$ decorated with aromatic functional groups. (a) 2,6-Lutidine, $\mathrm{Cu}\left(\mathrm{CH}_{3} \mathrm{CN}\right)_{4} \mathrm{PF}_{6}$, dry DCM, $21{ }^{\circ} \mathrm{C}, 3$ days.

The yields for the CuAAC of two aliphatic and of two aromatic residues are similar. Therefore, it is reasonable that neither flexibility nor rigidity is advantageous for this kind of reaction.

\subsection{CuAAC of Cyclic Peptoids and Small Molecules}

To increase the structural diversity of the tube-like tricyclic peptoids, small molecules were incorporated by tuning the size of the tube and allowing access to further functionalisation. For size enlargement of the cavity in between the macrocycles, 1,4-diethynylbenzene (10) was attached to peptoid $\mathbf{7 b}$ (Scheme 5). 


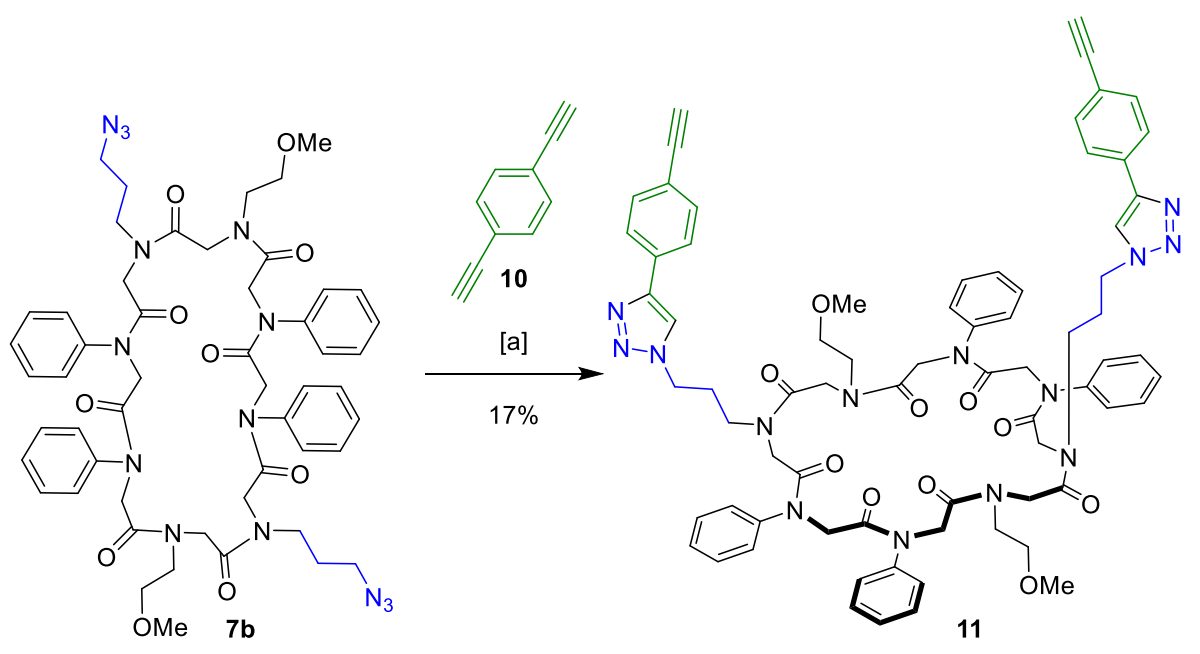

Scheme 5. CuAAC of the macrocyclic peptoid $7 \mathbf{b}$ and 1,4-diethynylbenzene (10). (a) 2,6-Lutidine, $\mathrm{Cu}\left(\mathrm{CH}_{3} \mathrm{CN}\right)_{4} \mathrm{PF}_{6}$, dry DCM, $21^{\circ} \mathrm{C}, 3$ days.

The bifunctionalised linker $\mathbf{1 0}$ was added in excess to enable full conversion and to circumvent intramolecular crosslinking. The reaction conditions complied with the ones mentioned for the CuAAC of the two peptoid macrocycles. Compound $\mathbf{1 1}$ was isolated in $17 \%$ yield after purification. Product formation was verified via MALDI-TOF and purity was determined to be $99 \%$. The CuAAC of linker conjugate $\mathbf{1 1}$ and another azide-functionalised peptoid macrocycle failed.

To enable further structural diversity that was adjustable via light, an azobenzene linker system was synthesised according to a published procedure [53]. Azobenzenes are known for their ability to switch their conformation from cis to trans and vice versa after irradiation with light $[54,55]$. They have been used as submonomers in solid-phase synthesis and have been shown to affect the structure of the resulting peptoid derivatives due to triggerable cis-trans-isomerisation [56].

The effectivity of the conformational change after UV radiation was monitored via NMR for the synthesised linker (see Supplementary Materials). The potent azobenzene should then be incorporated as a spacer between two macrocycles. So far, examples for only linear peptoids with an azobenzene switch have been found [56]. Herein, we report the first peptoid macrocycle attached to an azobenzene. Conjugate 13 (Scheme 6) was synthesised via CuAAC according to the conditions mentioned above. Product $\mathbf{1 3}$ was obtained in 19\% yield and $98 \%$ purity, similarly to the yield obtained for the CuAAC of the simplified linker 10 (Scheme 5). 

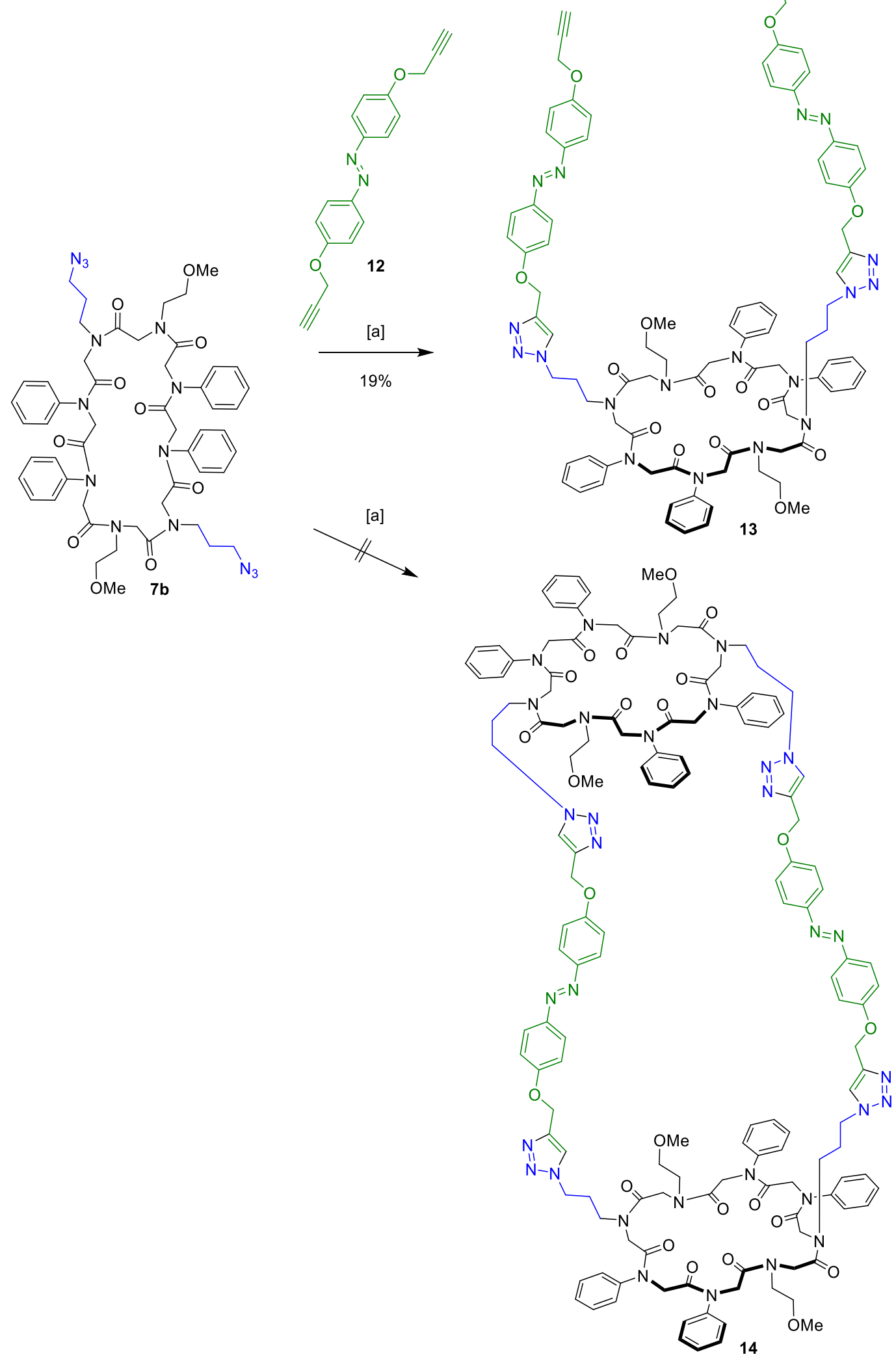

Scheme 6. CuAAC of the cyclic peptoid $7 \mathbf{b}$ and the azobenzene linker 12 revealed conjugate 13, but did not form the tricyclic structure 14. (a) 2,6-Lutidine, $\mathrm{Cu}\left(\mathrm{CH}_{3} \mathrm{CN}\right)_{4} \mathrm{PF}_{6}$, dry $\mathrm{DCM}, 21^{\circ} \mathrm{C}, 3$ days. 
The subsequent switch experiments should confirm the conformational change of the entire system 13. NMR spectra of product 13 both before and after irradiation with UV light were measured (Figure 4).

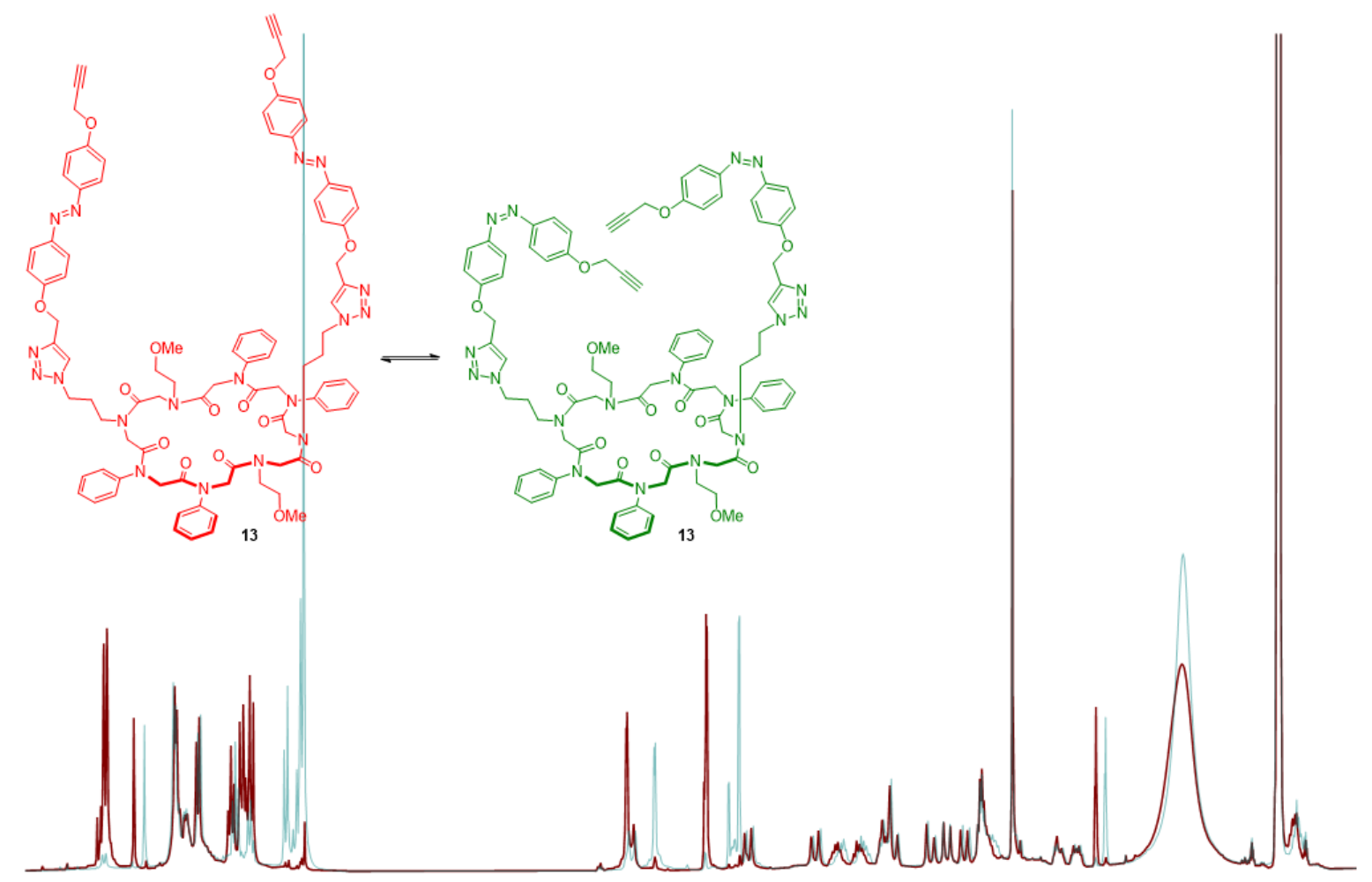

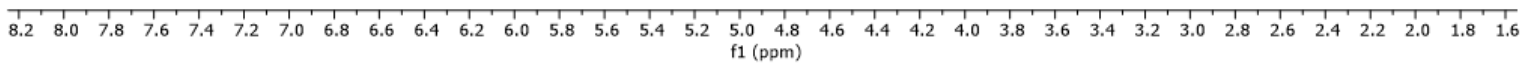

Figure 4. Switch experiment of conjugate 13, whose conformation change from trans (red) to cis (green) after irradiation with UV light was monitored via nuclear magnetic resonance (NMR).

Significant changes in the aromatic area were observed. Additionally, the signals of the terminal alkyne and methylene groups of the azobenzene linkers shifted. UVVis measurements verified these results (see Supplementary Materials). Therefore, the azobenzene of conjugate $\mathbf{1 3}$ can switch efficaciously from trans- to cis-conformation after irradiation with UV light.

Unfortunately, the desired tricyclic structure 14 with one peptoid macrocycle attached to each alkyne moiety of the azobenzene linker could not be isolated (Scheme 6). It is conceivable that the chosen linker system is unable to close the tricyclic tube via CuAAC due to its high degree of flexibility. Compound $\mathbf{1 3}$ polymerised to an insoluble solid instead.

To circumvent polymerisation, a rigidified azobenzene linker system was synthesised according to a procedure known from the literature [57]. Switch experiments revealed conformational changes with effectivities of $97 \%$ for trans- and $95 \%$ cis-conformers (see Supplementary Materials).

The CuAAC of the rigidified linker and peptoid $7 \mathbf{b}$ was carried out as described before, using an excess of the azobenzene linker to circumvent intramolecular crosslinking. After three days, macrocycle $\mathbf{1 5}$ and the tube-like structure $\mathbf{1 6}$ were isolated (Figure 5). 


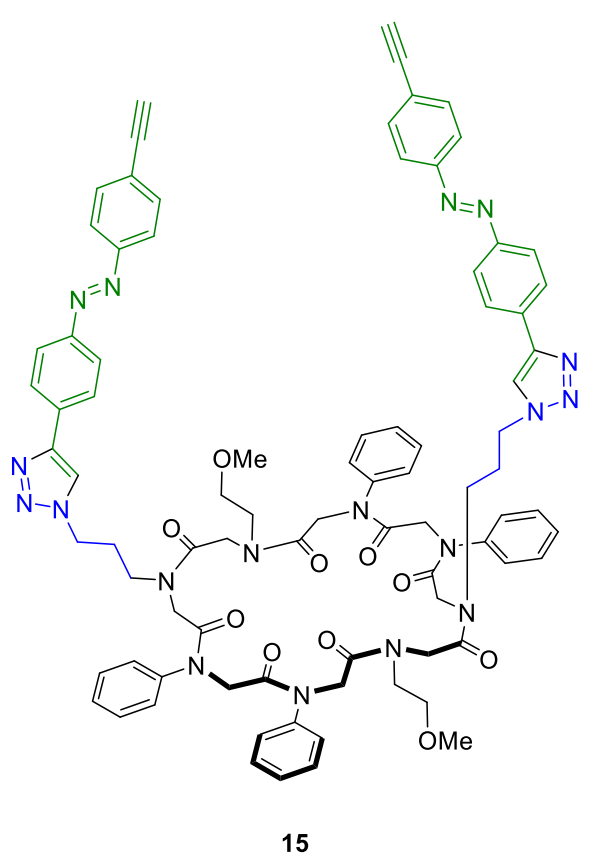

(a)

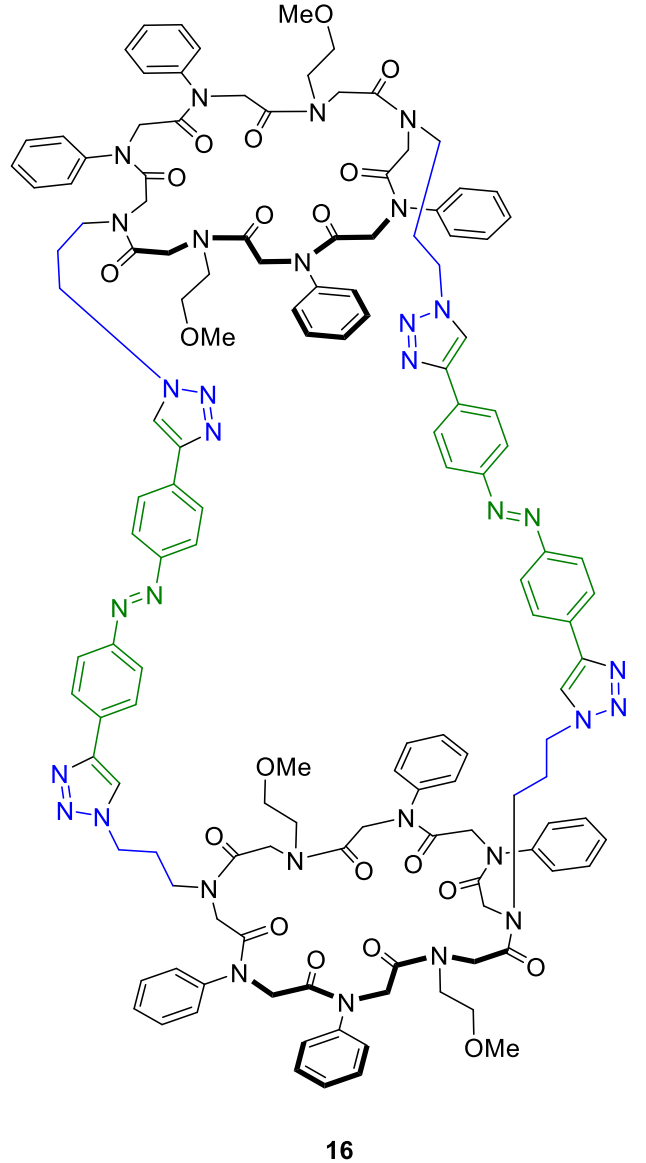

(b)

Figure 5. Products of the CuAAC of peptoid $\mathbf{7 b}$ and a rigidified azobenzene linker (green). (a) Conjugate $\mathbf{1 5}$ displays the linker with one peptoid macrocycle attached to one alkyne moiety each. (b) CuAAC of both alkyne moieties led to the tube-like structure 16.

Structure 15 with peptoid conjugation to one alkyne moiety of the azobenzene linker was obtained in $3 \%$ yield after purification. Interestingly, the yield is significantly less compared to the CuAAC of the more flexible azobenzene linker $\mathbf{1 2}$ described above. In return, the desired tube-like tricyclic peptoid structure $\mathbf{1 6}$ was additionally obtained in a similar yield of $2 \%$. Masses of both products were confirmed via MALDI-TOF and electrospray ionization (ESI-TOF). NMR measurements verified the receipt of the single structures (see Supplementary Materials).

Switch experiments of both molecules were monitored via NMR after irradiation with UV light $(365 \mathrm{~nm})$ for $30 \mathrm{~min}$. The conformational change from trans to cis was verified by significant shifts in the aromatic region (Figure 6). In the case of product 15, an additional signal shift of the terminal alkyne proton was observable after irradiation (see Supplementary Materials). 

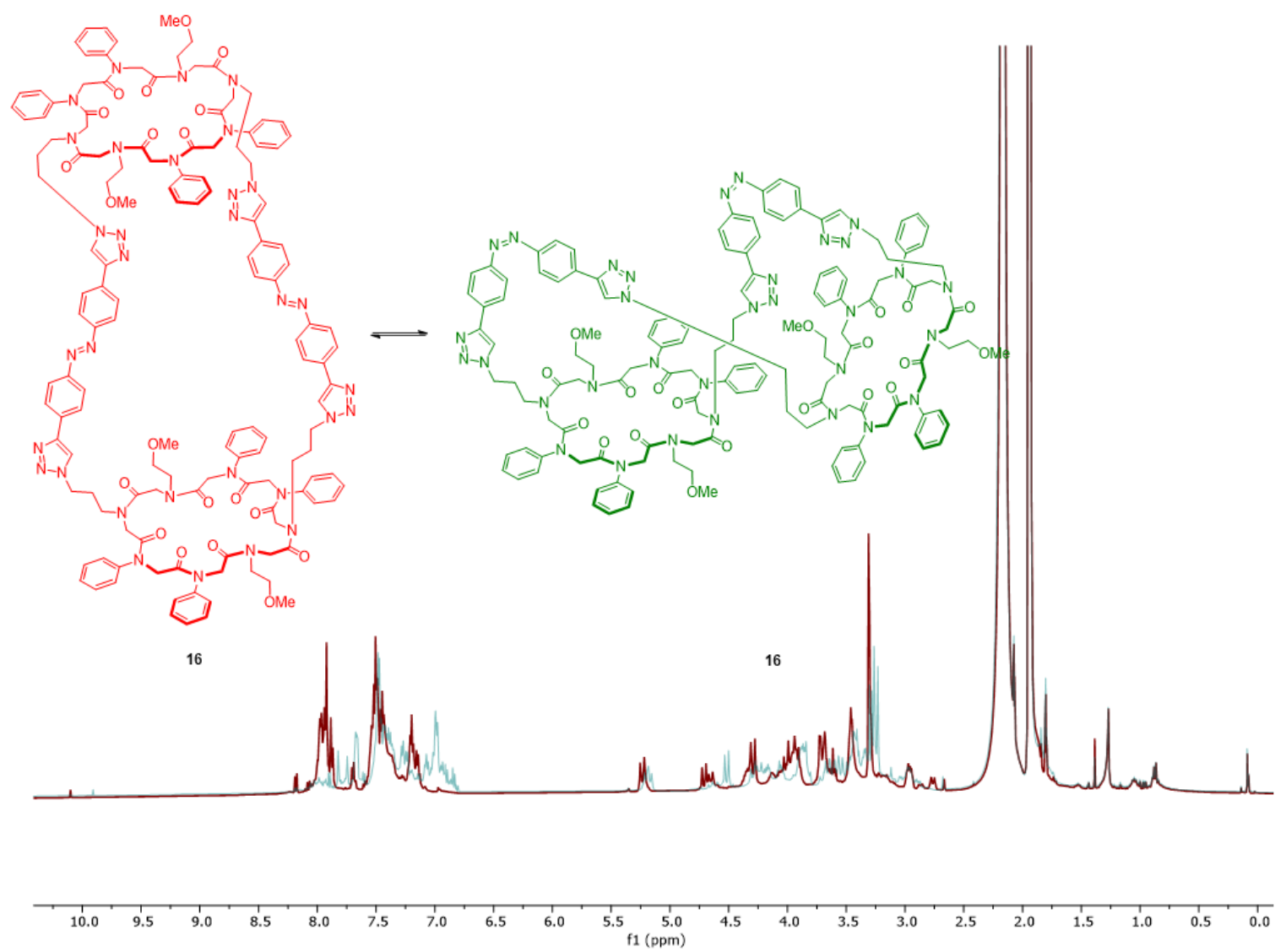

Figure 6. Switch experiment of the tricyclic structure 16, whose conformation change from trans (red) to cis (green) after irradiation with UV light was monitored via NMR.

Additionally, UV-Vis spectra of compounds $\mathbf{1 5}$ and $\mathbf{1 6}$ were recorded before and after irradiation with UV light (Figure 7 and Supplementary Materials).

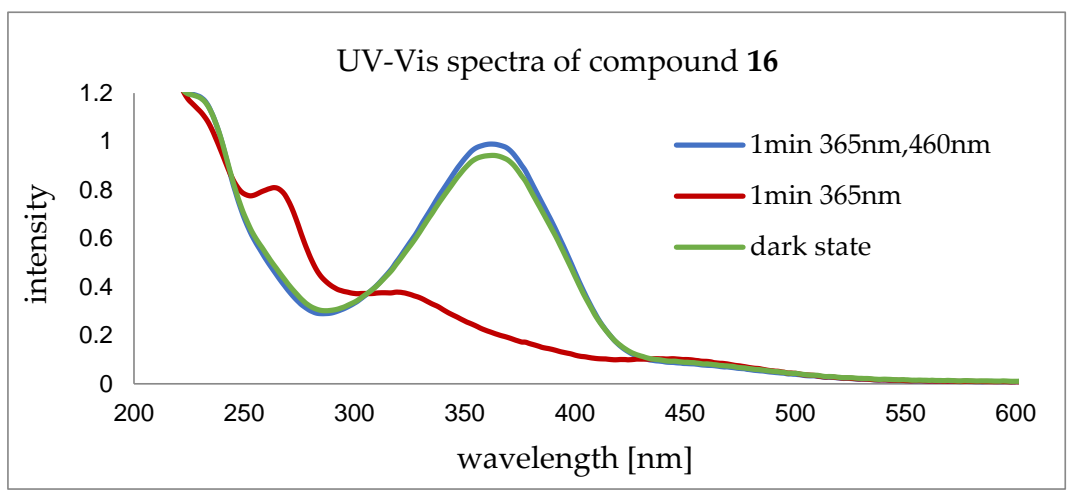

Figure 7. UV-Vis spectra of compound 16 before (green) and after irradiation with UV light (365 nm) for $1 \mathrm{sec}$ (red), indicating a conformational change from trans to cis. The reverse conformational change was induced via irradiation with UV light $(365 \mathrm{~nm})$, followed by irradiation with visible light (460 nm) for $1 \mathrm{~min}$ each (blue).

Trans-conformation is indicated by the dark state trace. Conformational change towards the cis-conformation was triggered by irradiation with UV light $(365 \mathrm{~nm})$ for $1 \mathrm{~min}$. Reverse conformational change from cis to trans was monitored after irradiation with UV light $(365 \mathrm{~nm})$ first to force the azobenzene into cis, with subsequent irradiation with visible light $(460 \mathrm{~nm})$ for $1 \mathrm{~min}$ each. 
When changing conformation from trans to cis, a significant increase in intensity is observable at around $280 \mathrm{~nm}$. A decrease occurs simultaneously at around $360 \mathrm{~nm}$. The trace of the probe irradiated with UV light first and with visible light next corroborates the transfer from cis to trans, showing the reversibility of the system.

These results give evidence of a reversible conformational switch of the tricyclic peptoid 16. With this, the tube-like structure can open and close, rendering it applicable for storage or host-guest chemistry.

\section{Materials and Methods}

General procedure for the synthesis of cyclic peptoids: In a fritted syringe, a 2chlorotrityl-chloride resin $(300 \mathrm{mg}, 0.480 \mathrm{mmol}, 1.60 \mathrm{mmol} / \mathrm{mg}$ loading density, 100-200 mesh, 1.00 equiv.) was swollen in $3 \mathrm{~mL}$ of methylene chloride (DCM) for $2 \mathrm{~h}$. After filtration, a freshly prepared solution of bromoacetic acid (2.59 mmol, 5.40 equiv.) and $N, N^{\prime}$-diisopropylethylamine (DIPEA, $2.59 \mathrm{mmol}, 5.40$ equiv.) in $2.5 \mathrm{~mL}$ of DCM was added and shaken for $1 \mathrm{~h}$ at $21^{\circ} \mathrm{C}$. The resin was extensively washed with peptide-grade $N, N^{\prime}$-dimethyl-formamide ( $\left.p \mathrm{DMF}\right)$. For the following substitution reaction, a solution of the corresponding amine ( $3.98 \mathrm{mmol}, 8.30$ equiv.) in $2.5 \mathrm{~mL}$ of $p$ DMF was added to the resin and shaken for $30 \mathrm{~min}$ at room temperature (overnight in the case of aniline). Following extensive washing with $p \mathrm{DMF}$, a solution of bromoacetic acid (4.80 mmol, 10.0 equiv.) and $N, N^{\prime}$-diisopropylcarbodiimide (DIC, $4.80 \mathrm{mmol}, 10.0$ equiv.) in $2.5 \mathrm{~mL} p \mathrm{DMF}$ were added and shaken for $30 \mathrm{~min}$ at room temperature ( $2 \mathrm{~h}$ in the case of aniline). The acetylation and substitution steps were alternated repeatedly until the desired peptoid length was achieved. For cleavage, a solution of 33\% hexafluoroisopropanol in DCM was added and the mixture was shaken overnight. The solvent was removed under reduced pressure.

For cyclisation, the activating agent benzotriazol-1-yl-oxytripyrrolidino-phosphonium hexafluorophosphate (PyBOP, $1.44 \mathrm{mmol}, 3.00$ equiv.) and DIPEA (2.88 mmol, 6.00 equiv.) were added to a solution of the respective peptoid in $100 \mathrm{~mL}$ of DCM. The solution was stirred overnight at room temperature, and the solvent was removed under reduced pressure. The residue was dissolved in a mixture of acetonitrile/water (1:1), lyophilised, and purified via preparative reverse-phase HPLC.

General procedure for the CuAAC of the two peptoids: Both the peptoid decorated with azide (1.00 equiv.) and the one decorated with alkyne moieties (1.00 equiv.) were dissolved in dry DCM and degassed with argon. Afterwards, 2,6-lutidine (6.00 equiv.) was added and the solution was stirred for $5 \mathrm{~min}$. Finally, tetrakis(acetonitrile)copper(I) hexafluorophosphate $\left(\mathrm{Cu}\left(\mathrm{CH}_{3} \mathrm{CN}\right)_{4} \mathrm{PF}_{6}, 1.00\right.$ equiv.) was added, and the mixture was stirred for 3 days at room temperature. The solvent was removed under reduced pressure and the residue was purified via preparative reverse-phase HPLC.

General procedure for the CuAAC of a linker and a peptoid: The desired peptoid (1.00 equiv.) and the respective linker (10.0 equiv.) were dissolved in dry DCM and degassed with argon for $10 \mathrm{~min}$. Afterwards, 2,6-lutidine (8.00 equiv.) was added and the solution was stirred for $5 \mathrm{~min}$. Finally, $\mathrm{Cu}\left(\mathrm{CH}_{3} \mathrm{CN}\right)_{4} \mathrm{PF}_{6}(1.00$ equiv.) was added and the mixture was stirred for 3 days at room temperature. The solvent was removed under reduced pressure and the residue was purified via preparative reverse-phase HPLC.

Switch experiments via NMR: The sample was dissolved in deuterated acetonitrile and stored under exclusion of light. Measurements were performed on a Bruker 500 spectrometer at $500 \mathrm{MHz}$. Spectra were recorded before and after irradiation with UV light (365 nm).

Switch experiments via UV-Vis: $20 \mu \mathrm{M}$ solutions of the single samples were stored in the dark. Measurements were performed on a PerkinElmer Lambda 750 UV/Vis/NIR spectrometer and monitored in the range from 200 to $800 \mathrm{~nm}$ wavelength. Spectra were monitored before and after irradiation with UV and visible light, respectively. 


\section{Crystal Structure Determinations}

The single-crystal X-ray diffraction study was carried out on a Bruker D8 Venture diffractometer with a Photon100 detector at 123(2) K (7b) and an Agilent SuperNovaDual diffractometer with an Atlas CCD-detector at $120(2) \mathrm{K}(7 \mathrm{~b})$ using $\mathrm{Cu}-\mathrm{K} \alpha$ radiation $(\lambda=1.54178 \AA$ A). (Bruker AXS GmbH, Karlsruhe, Germany] Agilent Technologies, Oxford, United Kingdom) Dual-Space Methods (SHELXD) (for 7b) or Direct methods (SHELXS-97) (for 7c) (SHELXD and SHELXS [58]) were used for the structure solution, and refinement was carried out using SHELXL-2013 or SHELXL-2014 (full-matrix least-squares on $F^{2}$ ) (SHELXL [59]). Hydrogen atoms were refined using a riding model (H(water) free). Semiempirical absorption corrections were applied. For $\mathbf{7 b}$, an extinction correction was applied. In $7 \mathbf{b}$, the solvent water and the two 3-azidopropyl groups were disordered (see cif-file for details). In 7c, the absolute structure could not be determined reliably (Parsons $\mathrm{x}$-parameter, $\mathrm{x}=0.5(2)$; see cif-file for details) [60].

$7 \mathrm{~b}$ : colourless crystals, $\mathrm{C}_{52} \mathrm{H}_{62} \mathrm{~N}_{14} \mathrm{O}_{10}-0.5 \mathrm{H}_{2} \mathrm{O}, \mathrm{M}_{\mathrm{r}}=1052.16$, crystal size $0.36 \times 0.12 \times 0.06 \mathrm{~mm}$, monoclinic, space group $C 2 / c$ (No. 15), $a=23.0990(10) \AA$, $b=18.4326(8) \AA, c=25.4929(12) \AA, \beta=105.159(2)^{\circ}, V=10476.5(8) \AA^{3}, Z=8$, $\rho=1.334 \mathrm{Mg} / \mathrm{m}^{-3}, \mu\left(\mathrm{Cu}-\mathrm{K}_{\alpha}\right)=0.789 \mathrm{~mm}^{-1}, F(000)=4456,2 \theta_{\max }=145.4^{\circ}, 50,224$ reflections, of which 10,350 were independent $\left(R_{\text {int }}=0.073\right), 687$ parameters, 51 restraints, $R_{1}=0.090$ (for $8336 \mathrm{I}>2 \sigma(\mathrm{I})$ ), $\mathrm{w} R_{2}=0.228$ (all data), $S=1.04$, largest diff. peak $/$ hole $=1.196$ (in disordered 3-azidopropyl)/ -0.772 e $\AA^{-3}$.

7c: colourless crystals, $\mathrm{C}_{56} \mathrm{H}_{64} \mathrm{~N}_{8} \mathrm{O}_{12}, M_{\mathrm{r}}=1041.15$, crystal size $0.19 \times 0.08 \times 0.04 \mathrm{~mm}$, orthorhombic, space group $P_{c a 2}$ (No. 29), $a=36.3213(8) \AA, b=9.1548(3) \AA, c=32.2512(7) \AA$, $V=10724.0(5) \AA^{3}, Z=8, \rho=1.290 \mathrm{Mg} / \mathrm{m}^{-3}, \mu\left(\mathrm{Cu}-\mathrm{K}_{\alpha}\right)=0.754 \mathrm{~mm}^{-1}, F(000)=4416$, $2 \theta_{\max }=152.4^{\circ}, 24,059$ reflections, of which 15,570 were independent $\left(R_{\text {int }}=0.043\right)$, 1369 parameters, 1 restraint, $R_{1}=0.079$ (for $12810 \mathrm{I}>2 \sigma(\mathrm{I})$ ), $\mathrm{w} R_{2}=0.214$ (all data), $S=1.03$, largest diff. peak $/$ hole $=0.851 /-0.306 \mathrm{e} \AA^{-3}$.

Cambridge Chrystallographic Data Centre (CCDC) 1446764 (7b) and 1446765 (7c) contain the supplementary crystallographic data for this paper. These data can be obtained free of charge from The Cambridge Crystallographic Data Centre via www.ccdc.cam.ac. uk/data_request/cif.

\section{Conclusions}

Herein, we report the successful synthesis of tube-like tricyclic peptoids via CuAAC, giving access to novel secondary structures. An azobenzene linker system was successfully incorporated as a spacer between two macrocycles. The opportunity to modify the linkage makes the structures tuneable in size and enables the introduction of functional centres. The azobenzene changed its conformation reversibly from trans to cis after irradiation with UV and visible light, respectively. With this, the tricyclic structure was forced into bot an open and a closed conformation. This switch was verified using NMR experiments and UV-Vis measurements. Hence, this new class of tube-like peptoid structures gives access to host-guest applications or controllable storage of small molecules.

Supplementary Materials: The following are available online: synthetic procedure, switch experiments.

Author Contributions: Conceptualisation, C.N.H. and K.S.; methodology, K.S.; validation, S.B.; formal analysis, K.S., P.W., and M.N.; investigation, K.S.; resources, S.B.; data curation, C.N.H., K.S., and M.N.; writing—original draft preparation, C.N.H. and K.S.; writing-review and editing, C.N.H. and S.B.; visualisation, C.N.H.; supervision, S.B.; project administration, S.B.; funding acquisition, S.B. All authors have read and agreed to the published version of the manuscript.

Funding: We acknowledge support from the KIT, the DAAD, and the DFG (SFB 1176, EXC-2082/1390761711).

Institutional Review Board Statement: Not applicable.

Informed Consent Statement: Not applicable. 
Data Availability Statement: The data presented in this study are openly available in the Chemotion repository: www.chemotion-repository.net.

Acknowledgments: We thank Kent Kirshenbaum (New York) for fruitful discussions.

Conflicts of Interest: The authors declare no conflict of interest.

Sample Availability: The molecules are deposited at the Compound Platform of the KIT. Selected molecules are available on request.

\section{References}

1. Shin, S.B.; Yoo, B.; Todaro, L.J.; Kirshenbaum, K. Cyclic peptoids. J. Am. Chem. Soc. 2007, 129, 3218-3225. [CrossRef] [PubMed]

2. Yoo, B.; Shin, S.B.Y.; Huang, M.L.; Kirshenbaum, K. Peptoid macrocycles: Making the rounds with peptidomimetic oligomers. Chem. Eur. J. 2010, 16, 5528-5537. [CrossRef] [PubMed]

3. Webster, A.M.; Cobb, S.L. Recent advances in the synthesis of peptoid macrocycles. Chem. Eur. J. 2018, 24, 7560-7573. [CrossRef]

4. Baldauf, C.; Günther, R.; Hofmann, H.-J. Helices in peptoids of $\alpha$-and $\beta$-peptides. Phys. Biol. 2006, 3, 1-9. [CrossRef] [PubMed]

5. Sanborn, T.J.; Wu, C.W.; Zuckermann, R.N.; Barron, A.E. Extreme stability of helices formed by water-soluble poly-n-substituted glycines (polypeptoids) with $\alpha$-chiral side chains. Biopolymers 2002, 63, 12-20. [CrossRef] [PubMed]

6. Stringer, J.R.; Crapster, J.A.; Guzei, I.A.; Blackwell, H.E. Extraordinarily robust polyproline type i peptoid helices generated via the incorporation of $\alpha$-chiral aromatic n-1-naphthylethyl side chains. J. Am. Chem. Soc. 2011, 133, 15559-15567. [CrossRef]

7. Mannige, R.V.; Haxton, T.K.; Proulx, C.; Robertson, E.J.; Battigelli, A.; Butterfoss, G.L.; Zuckermann, R.N.; Whitelam, S. Peptoid nanosheets exhibit a new secondary-structure motif. Nature 2015, 526, 415-420. [CrossRef]

8. Robertson, E.J.; Oliver, G.K.; Qian, M.; Proulx, C.; Zuckermann, R.N.; Richmond, G.L. Assembly and molecular order of two-dimensional peptoid nanosheets through the oil-water interface. Proc. Natl. Acad. Sci. USA 2014, 111, 13284-13289. [CrossRef]

9. Kudirka, R.; Tran, H.; Sanii, B.; Nam, K.T.; Choi, P.H.; Venkateswaran, N.; Chen, R.; Whitelam, S.; Zuckermann, R.N. Folding of a single-chain, information-rich polypeptoid sequence into a highly ordered nanosheet. Biopolymers 2011, 96, 586-595. [CrossRef]

10. Sanii, B.; Kudirka, R.; Cho, A.; Venkateswaran, N.; Olivier, G.K.; Olson, A.M.; Tran, H.; Harada, R.M.; Tan, L.; Zuckermann, R.N. Shaken, not stirred: Collapsing a peptoid monolayer to produce free-floating, stable nanosheets. J. Am. Chem. Soc. 2011, 133, 20808-20815. [CrossRef]

11. Smith, P.T.; Huang, M.L.; Kirshenbaum, K. Osmoprotective polymer additives attenuate the membrane pore-forming activity of antimicrobial peptoids. Biopolymers 2015, 103, 227-236. [CrossRef] [PubMed]

12. Huang, M.L.; Shin, S.B.Y.; Benson, M.A.; Torres, V.J.; Kirshenbaum, K. A comparison of linear and cyclic peptoid oligomers as potent antimicrobial agents. ChemMedChem 2012, 7, 114-122. [CrossRef] [PubMed]

13. Chongsiriwatana, N.P.; Patch, J.A.; Czyzewski, A.M.; Dohm, M.T.; Ivankin, A.; Gidalevitz, D.; Zuckermann, R.N.; Barron, A.E. Peptoids that mimic the structure, function, and mechanism of helical antimicrobial peptides. Proc. Natl. Acad. Sci. USA 2008, 105, 2794-2799. [CrossRef] [PubMed]

14. Bolt, H.L.; Eggimann, G.A.; Jahoda, C.A.B.; Zuckermann, R.N.; Sharples, G.J.; Cobb, S.L. Exploring the links between peptoid antibacterial activity and toxicity. MedChem Comm 2017, 8, 886-896. [CrossRef] [PubMed]

15. Mojsoska, B.; Jenssen, H. Peptides and peptidomimetics for antimicrobial drug design. Pharmaceuticals 2015, 8, 366-415. [CrossRef]

16. Mojsoska, B.; Zuckermann, R.N.; Jenssen, H. Structure-activity relationship study of novel peptoids that mimic the structure of antimicrobial peptides. Antimicrob. Agents Chemother. 2015, 59, 4112-4120. [CrossRef]

17. Czyzewski, A.M.; Jenssen, H.; Fjell, C.D.; Waldbrook, M.; Chongsiriwatana, N.P.; Yuen, E.; Hancock, R.E.; Barron, A.E. In vivo, in vitro, and in silico characterization of peptoids as antimicrobial agents. PLoS ONE 2016, 11, e0135961. [CrossRef]

18. Jahnsen, R.D.; Frimodt-Moller, N.; Franzyk, H. Antimicrobial activity of peptidomimetics against multidrug-resistant Escherichia coli: A comparative study of different backbones. J. Med. Chem. 2012, 55, 7253-7261. [CrossRef]

19. Mojsoska, B.; Carretero, G.; Larsen, S.; Mateiu, R.V.; Jenssen, H. Peptoids successfully inhibit the growth of gram negative E. coli causing substantial membrane damage. Sci. Rep. 2017, 7, 42332. [CrossRef]

20. Bicker, K.L.; Cobb, S.L. Recent advances in the development of anti-infective peptoids. Chem. Comm. 2020, 56, 11158-11168. [CrossRef]

21. Molchanova, N.; Nielsen, J.E.; Sørensen, K.B.; Prabhala, B.K.; Hansen, P.R.; Lund, R.; Barron, A.E.; Jenssen, H. Halogenation as a tool to tune antimicrobial activity of peptoids. Sci. Rep. 2020, 10, 1-10. [CrossRef] [PubMed]

22. Nam, H.Y.; Choi, J.; Kumar, S.D.; Nielsen, J.E.; Kyeong, M.; Wang, S.; Kang, D.; Lee, Y.; Lee, J.; Yoon, M.-H. Helicity modulation improves the selectivity of antimicrobial peptoids. ACS Infect. Dis. 2020, 6, 2732-2744. [CrossRef] [PubMed]

23. Khara, J.S.; Mojsoska, B.; Mukherjee, D.; Langford, P.R.; Robertson, B.D.; Jenssen, H.; Ee, P.L.R.; Newton, S.M. Ultra-short antimicrobial peptoids show propensity for membrane activity against multi-drug resistant mycobacterium tuberculosis. Front. Microbol. 2020, 11, 417. [CrossRef] [PubMed]

24. Dohm, M.T.; Kapoor, R.; Barron, A.E. Peptoids: Bio-inspired polymers as potential pharmaceuticals. Curr. Pharm. Des. 2011, 17, 2732-2747. [CrossRef] [PubMed]

25. Zuckermann, R.N.; Kodadek, T. Peptoids as potential therapeutics. Curr. Opin. Mol. Ther. 2009, 11, $299-307$.

26. Rhodes, C.A.; Pei, D. Bicyclic peptides as next-generation therapeutics. Chem. Eur. J. 2017, 23, 12690-12703. [CrossRef] 
27. Luo, Y.; Song, Y.; Wang, M.; Jian, T.; Ding, S.; Mu, P.; Liao, Z.; Shi, Q.; Cai, X.; Jin, H. Bioinspired peptoid nanotubes for targeted tumor cell imaging and chemo-photodynamic therapy. Small 2019, 15, 1902485. [CrossRef]

28. Maayan, G.; Ward, M.D.; Kirshenbaum, K. Folded biomimetic oligomers for enantioselective catalysis. Proc. Natl. Acad. Sci. USA 2009, 106, 13679-13684. [CrossRef]

29. Drapaneni, C.; Ghosh, P.; Ghosh, T.; Maayan, G. Unique $\beta$-turn peptoid structures and their application as asymmetric catalysts. Chem. Eur. J. 2020, 26, 9573-9579. [CrossRef]

30. Olivier, G.K.; Cho, A.; Sanii, B.; Connolly, M.D.; Tran, H.; Zuckermann, R.N. Antibody-mimetic peptoid nanosheets for molecular recognition. ACS Nano 2013, 7, 9276-9286. [CrossRef]

31. Liu, J.; Cai, B.; Cui, L.; Chen, C.-L. Peptoid-based hierarchically-structured biomimetic nanomaterials: Synthesis, characterization and applications. Sci. China Mater. 2020, 63, 1099-1112. [CrossRef]

32. Battigelli, A.; Kim, J.H.; Dehigaspitiya, D.C.; Proulx, C.; Robertson, E.J.; Murray, D.J.; Rad, B.; Kirshenbaum, K.; Zuckermann, R.N. Glycosylated peptoid nanosheets as a multivalent scaffold for protein recognition. ACS Nano 2018, 12, 2455-2465. [CrossRef] [PubMed]

33. Kim, J.H.; Kim, S.C.; Kline, M.A.; Grzincic, E.M.; Tresca, B.W.; Cardiel, J.; Karbaschi, M.; Dehigaspitiya, D.C.; Chen, Y.; Udumula, V. Discovery of stable and selective antibody mimetics from combinatorial libraries of polyvalent, loop-functionalized peptoid nanosheets. ACS Nano 2019, 14, 185-195. [CrossRef] [PubMed]

34. Wang, M.; Song, Y.; Mu, P.; Cai, X.; Lin, Y.; Chen, C.-L. Peptoid-based programmable 2d nanomaterial sensor for selective and sensitive detection of h2s in live cells. ACS Appl. Bio Mater. 2020, 3, 6039-6048. [CrossRef]

35. Zuckermann, R.N.; Kerr, J.M.; Kent, S.B.H.; Moos, W.H. Efficient method for the preparation of peptoids [oligo(n-substituted glycines)] by submonomer solid-phase synthesis. J. Am. Chem. Soc. 1992, 114, 10646-10647. [CrossRef]

36. Butterfoss, G.L.; Renfrew, P.D.; Kuhlman, B.; Kirshenbaum, K.; Bonneau, R. A preliminary survey of the peptoid folding landscape. J. Am. Chem. Soc. 2009, 131, 16798-16807. [CrossRef]

37. Vollrath, S.B.; Bräse, S.; Kirshenbaum, K. Twice tied tight: Enforcing conformational order in bicyclic peptoid oligomers. Chem. Sci. 2012, 3, 2726-2731. [CrossRef]

38. Vollrath, S.B.; Hu, C.; Bräse, S.; Kirshenbaum, K. Peptoid nanotubes: An oligomer macrocycle that reversibly sequesters water via single-crystal-to-single-crystal transformations. Chem. Comm. 2013, 49, 2317-2319. [CrossRef]

39. Shah, N.H.; Butterfoss, G.L.; Nguyen, K.; Yoo, B.; Bonneau, R.; Rabenstein, D.L.; Kirshenbaum, K. Oligo(n-aryl glycines): A new twist on structured peptoids. J. Am. Chem. Soc. 2008, 130, 16622-16632. [CrossRef]

40. Wijaya, A.W.; Nguyen, A.I.; Roe, L.T.; Butterfoss, G.L.; Spencer, R.K.; Li, N.K.; Zuckermann, R.N. Cooperative intramolecular hydrogen bonding strongly enforces cis-peptoid folding. J. Am. Chem. Soc. 2019, 141, 19436-19447. [CrossRef]

41. Knight, A.S.; Zhou, E.Y.; Francis, M.B.; Zuckermann, R.N. Sequence programmable peptoid polymers for diverse materials applications. Adv. Mater. 2015, 27, 5665-5691. [CrossRef] [PubMed]

42. Kolaskar, A.; Lakshminarayanan, A.; Sarathy, K.; Sasisekharan, V. The nonplanar peptide unit iii. Quantum chemical calculations for related compounds and experimental x-ray diffraction data. Biopolymers 1975, 14, 1081-1094. [CrossRef] [PubMed]

43. D'Amato, A.; Pierri, G.; Tedesco, C.; Della Sala, G.; Izzo, I.; Costabile, C.; De Riccardis, F. Reverse turn and loop secondary structures in stereodefined cyclic peptoid scaffolds. J. Org. Chem. 2019, 84, 10911-10928. [CrossRef] [PubMed]

44. De Riccardis, F. The challenge of conformational isomerism in cyclic peptoids. Eur. J. Org. Chem. 2020, 2020, 2981-2994. [CrossRef]

45. D'Amato, A.; Della Sala, G.; Izzo, I.; Costabile, C.; Masuda, Y.; De Riccardis, F. Cyclic octamer peptoids: Simplified isosters of bioactive fungal cyclodepsipeptides. Molecules 2018, 23, 1779. [CrossRef]

46. Tedesco, C.; Erra, L.; Izzo, I.; De Riccardis, F. Solid state assembly of cyclic $\alpha$-peptoids. CrystEngComm 2014, 16, 3667-3687. [CrossRef]

47. Schettini, R.; Costabile, C.; Della Sala, G.; Iuliano, V.; Tedesco, C.; Izzo, I.; De Riccardis, F. Cation-induced molecular switching based on reversible modulation of peptoid conformational states. J. Org. Chem. 2018, 83, 12648-12663. [CrossRef]

48. Yoo, B.; Kirshenbaum, K. Peptoid architectures: Elaboration, actuation, and application. Curr. Opin. Chem. Biol. $2008,12,714-721$. [CrossRef]

49. Haldón, E.; Nicasio, M.C.; Pérez, P.J. Copper-catalysed azide-alkyne cycloadditions (cuaac): An update. Org. Biomol. Chem. 2015, 13, 9528-9550. [CrossRef]

50. Liang, L.; Astruc, D. The copper(i)-catalyzed alkyne-azide cycloaddition (cuaac) "click" reaction and its applications. An overview. Coord. Chem. Rev. 2011, 255, 2933-2945. [CrossRef]

51. Holub, J.M.; Jang, H.; Kirshenbaum, K. Fit to be tied: Conformation-directed macrocyclization of peptoid foldamers. Org. Lett. 2007, 9, 3275-3278. [CrossRef] [PubMed]

52. Jagasia, R.; Holub, J.M.; Bollinger, M.; Kirshenbaum, K.; Finn, M. Peptide cyclization and cyclodimerization by cui-mediated azide- alkyne cycloaddition. J. Org. Chem. 2009, 74, 2964-2974. [CrossRef] [PubMed]

53. Kordel, C.; Popeney, C.S.; Haag, R. Photoresponsive amphiphiles based on azobenzene-dendritic glycerol conjugates show switchable transport behavior. Chem. Comm. 2011, 47, 6584-6586. [CrossRef] [PubMed]

54. Liao, L.-X.; Stellacci, F.; McGrath, D.V. Photoswitchable flexible and shape-persistent dendrimers: Comparison of the interplay between a photochromic azobenzene core and dendrimer structure. J. Am. Chem. Soc. 2004, 126, 2181-2185. [CrossRef] [PubMed] 
55. Zeitouny, J.; Aurisicchio, C.; Bonifazi, D.; De Zorzi, R.; Geremia, S.; Bonini, M.; Palma, C.-A.; Samorì, P.; Listorti, A.; Belbakra, A. Photoinduced structural modifications in multicomponent architectures containing azobenzene moieties as photoswitchable cores. J. Mater. Chem. 2009, 19, 4715-4724. [CrossRef]

56. Shah, N.H.; Kirshenbaum, K. Photoresponsive peptoid oligomers bearing azobenzene side chains. Org. Biomol. Chem. 2008, 6, 2516-2521. [CrossRef]

57. Kimoto, A.; Iwasaki, K.; Abe, J. Formation of photoresponsive gold nanoparticle networks via click chemistry. Photochem. Photobiol. Sci. 2010, 9, 152-156. [CrossRef]

58. Sheldrick, G.M. A short history of shelx. Acta Crystallogr. Sect. A Found. Crystallogr. 2008, 64, 112-122. [CrossRef]

59. Sheldrick, G.M. Crystal structure refinement with shelxl. Acta Crystallogr. Sect. C Struct. Chem. 2015, 71, 3-8. [CrossRef]

60. Parsons, S.; Flack, H. Precise absolute-structure determination in light-atom crystals. Acta Crystallogr. Sect. A Found. Crystallogr. 2004, 60, 61. [CrossRef] 